\title{
Analysis of partnerships for actions intra-sectoral and inter-sectors for health in areas of high socio- environmental vulnerability in the city of São Paulo/Brazil: a mixed method study
}

Patricia Melo Bezerra ( $\sim$ patriciamelobe@gmail.com )

Faculdade de Medicina do ABC https://orcid.org/0000-0003-3667-5504

lara Coelho Zito Guerriero

Faculdade de Medicina do ABC

Research article

Keywords: Inter-sectoral Collaboration, Intra-sectoral Collaboration, Primary Health Care, Cities, Poverty Areas, Healthcare Disparities, Health and Vulnerability.

Posted Date: November 26th, 2019

DOI: https://doi.org/10.21203/rs.2.13974/v2

License: (c) (1) This work is licensed under a Creative Commons Attribution 4.0 International License.

Read Full License 


\section{Abstract}

Context: Since poverty areas are socioeconomic complex and limiting environments, there is a need to develop intra-sectoral and inter-sectoral actions in the health territory in order to achieve the economic and social well-being of people and society. This research aims to understand the relationship between inter-sectorial and inter-sectoral actions for health and socio-environmental groupings of the most vulnerable health territories in the city of São Paulo, identify which are the most frequent partners of these actions and how professionals experience these partnerships in their daily lives. Method: We adopted the mixed sequential and explanatory method. In the first phase, an online form was applied and identifies the Basic Health Units (BHU) that take place as intersectoral actions with more partners. In the second phase, we explored how the professionals consider the characteristics of the territory where they act to seek partnerships and how they carry out the actions. Results: Analysis of quantitative data indicated that: a) More than $98 \%$ of BHUs conduct intra- and inter-sectoral partnerships and b) there is no relationship between the indices of the most vulnerable groupings and the presence of intra- and intersectoral actions with statistical significance $p<0.05$. The content analysis of literal transcriptions pointed out that: intra- and inter-sectoral practices developed in the health territories were driven by the needs of the treatment of diseases or by the precarious conditions of life of individual or collectivities. However, in order to assist different types of violence, health professionals avoid seeking partnerships, including with the Tutelary Council and the Center for Human Rights, as they fear they will suffer reprisals by those who cause this violence. There was consistency between quantitative and qualitative data, except for partnership with education, other BHUs, environment, and the Tutelary Council. Conclusion: The construction of personalized partnerships for individual and collective health, in order to cope with social inequalities; of chronic diseases and by phases of the life cycle involved in socioeconomic fragilities that generate more poverty is part of the job from BHU's professionals.

\section{Background}

Inter-sectoral action on determinants of the health-disease and care process has long been recognized as an important factor in improving the health of the population. Facing health problems requires the search for partners and the implementation of effective intra-sectoral and inter-sectoral actions. Many experiences in different countries demonstrate the value of inter-sectoral action, where health efforts have been reinforced by involvement with other sectors, although few countries knowingly incorporate this action into their national health strategies(1).

Intra-sectoral actions are practices that arise from the need to improve the lives of people who are cared for by the health care network(2). Inter-sectoral actions aim to "achieve health outcomes in a more effective, efficient or sustainable way than the health sector could achieve by itself"(3). They seek to act within the social determinants of the health-disease and care process.

The social determinants of health (4) in spaces of vulnerability are too complex to be defined by one any single parameter and are difficult to study due to the numerous challenges facing both by geographical 
and social aspects. In these spaces, there are health problems that are transmissible, non-transmissible, and in addition, people suffer from violence and lack of presence of public authority responsible, which highlights the importance of intra-sectoral and inter-sectoral actions to address the diversity of these determinants(5). Partnerships between public health and other sectors effectively improve access to services for marginalized populations(6). Jone and Barry's definition of partnership conjecture with these studies by stating that partners can achieve more by working collaboratively so that partners' resources and complementary expertise produce effective solutions(7).

This research was developed in the city of São Paulo(SP)/Brazil, a multifaceted metropolis that despite being the largest Brazilian economy, presents a marked social inequality between its territories(8). It has $12,038,000$ inhabitants and is the eleventh largest population in the world. It has one of the highest densities in the world with 21.24 inhabitants/m2 and is the most populous in the American continent(9). One of the indicators of inequality is 'average per capita income' which presented the largest dispersion of the average among the city's health territories(8). Given the diversity of this mega-metropolis, the intraand inter-sectorial actions need to be evidenced in order to direct public policies to face health problems.

In this article, the concept of vulnerability is circumscribed by dynamic, social and multigenerational modes, based on both the risk intensity and the resilience of people considered beyond the risk perspective, allowing the dialogue with the intersectoriality(10). We have adopted the synthetic vulnerability indexes known as Socio-environmental Groupings in Health Territories (SGHT) because we understand that they are important tools in the active management of territories. These synthetic vulnerability indexes of the city of SP were elaborated by the Epidemiology and Information Coordination (CEInfo) with the objective of analyzing the health and life conditions and to know the possible factors associated to the population and health phenomena to subsidize the planning and management of health territories and other management levels of the Brazil's National Health System. In 2014 socioenvironmental groups of 449 health areas of the Basic Health Unit (BHU) were created considering the economic, social, urban and environmental dimensions. After significant factor analysis, a total of seven homogeneous groups were identified(8).

The scope areas of $\mathrm{BHU}$ are unique health territories where Primary Health Care (PHC) professionals can implement comprehensive network assistance (intra-sectoral actions) and with different sectors (intersectoral actions), guaranteeing the integrality of care and prioritizing the health promotion(11), although trust may be fragile between partners(12). In the type of Family Health Strategy (FHS) from the BHU, the professionals attend residents of a coverage area that are constituted by micro areas. Therefore, the micro area is the smallest territorial units in which the Community Health Agents ( $\mathrm{CHA}$ ) members of the FHS teams are mid-level health professionals who live and work in health promotion and surveillance practices in line with the multi-professional team(11).

International studies with different methods presented important conclusions on inter-sectoral practices. The World Health Organization conducted a study on inter-sectoral action for health in local government in low-, middle- and high-income countries and identified that these governments could provide a single 
scenario for the implementation of inter-sectoral activities, especially because of their proximity to people(13).

In another study, Kang aimed to analyze the characteristics and scope of inter-sectoral actions between physical activity programs in Healthy Cities compared to unhealthy Korean Cities and identified that Healthy Cities had a greater number of partners(14). The Healthy Cities local development strategy had a social pact as an intersectoral approach to address health determinants by committing to health promotion and improving the quality of life of the population(15). Tooher and colleagues sought to understand the processes and factors that influence inter-sectoral partnerships and point out that collaboration between complex systems, such as education and health, was a skilled enterprise that relied on a solid foundation of communication and interpersonal professional relationships to deliver expected results(16).

Studies on intersectorality in vulnerable areas in large Brazilian metropolises analyze different types of partnerships, for example, in Florianópolis, Heidemann and colleagues evaluate the achievements of the experience of community empowerment and point out that there are limitations to the integration of health promotion as an essential basis of community participatory practice(17). Becker and coauthors in Rio de Janeiro, analyze the work process in a BHU and conclude that professionals maintain curative, fragmented and individual care (18); and in the same metropolis Cohen and collaborators report experiences of health professionals as protagonists in the articulation between citizens and public housing policies in the search for healthy housing (19).

Despite the importance of inter-sectoral actions, the number of partners is still small. In a descriptive study of educational practices in the city of Belo Horizonte, Carneiro and coauthors indicate that only $9 \%$ carry out inter-sectoral actions(20). Moretti and collaborators using the mixed method showed that of the $67 \mathrm{BHU}$ of the city of Curitiba, $97 \%$ of the teams report inter-sectorial actions, however the content analysis carried out by the authors identifies that only $23.1 \%$ of the teams performed actions with intersectoral characteristics(21), which indicates that these professionals adopt different definitions of intersectoral actions, then those adopted by the authors of the study. Sá and collaborators conducted qualitative research in the BHU of the metropolitan region of João Pessoa and report the scarcity of these actions by FHS members(22).

Unlike other studies, this research aimed to understand the relationship between intra-sectoral and intersectoral actions for health and the socio-environmental groupings of the most vulnerable health territories in the city of São Paulo, identify which are the most frequent partners of these actions and how Professionals experience these partnerships in their daily lives through a two-step sequential mixed method.

Since poverty areas are complex and limiting socioeconomic environments, there is a need to develop intra-sectoral and inter-sectoral actions in health territory in order to achieve the well being of people and communities. In this way, we hypothesize that there is a relationship between the socio-environmental groups of the most vulnerable health areas and the existence of actions. 
The present research is relevant for Primary Health Care, for scientific knowledge in poverty areas and for society, since its results can subsidize practices among different sectors in health areas of the high vulnerability of large metropolises which presents an increasing tendency of these areas. It also points out potential partners to be conquered in complex contexts of high socio-environmental vulnerability.

\section{Methods}

The research method adopted, called explanatory sequential mixed was adapted from Jonh Creswell and Plano Clark (2011) having the following representation QUAN $\rightarrow$ qual(23). The adoption of the QUAN $\rightarrow$ qual strategy provided a more complete understanding of the research problem and the results of the quantitative phase were explored in the next phase. In the first phase, with the quantitative research, we identified the accomplishment or not of the inter-sectoral actions and the partnerships established for this purpose. The units that performed inter-sectoral actions were considered for the qualitative phase. In this second phase, we conducted observations and also focal groups(24) to explore how professionals characterize the territory in which they work, their potential partners, and how they perform intra-sectoral and inter-sectoral actions for health.

Figure 01 below represents the research design of the sequential explanatory and mixed method adopted. The question of mixed method leads to the question for quantitative method, data collection and first analysis of this phase. After the first analysis, the data are collected in a qualitative approach and the QUAN and "qual" data articulation are finally analyzed (23)(25).

\subsection{Data collect}

Primary data were collected from February to October 2018. Initially, we conducted a pilot study to adjust the multiple-choice form, which after the revision was used in the quantitative phase. From the analysis of the responses to the form, the BHU that met the selection criteria to start the qualitative phase was identified.

The selection criteria were: $\mathrm{BHU}$ who have been developing intra-sectoral and inter-sectoral practices for over two years and having the largest number of partners. The longevity of local public health improvement partnerships can be a way of anticipating the sense of the effectiveness of collaboration as indicated by Zahner. We adopted a period of 2 years to the research based on the local public health experience acquired by one of the researchers who has more than 20 years of experience in public health territories in Brazil and 12 years only in the city of São Paulo.

\subsubsection{Quantitative Phase: Pilot Test}

The multiple-choice form to be answered online was developed by the researchers. This instrument consisting of fifteen questions was divided into four parts. The first part addressed the characteristics of the BHU types in the city: Traditional BHU, Family Health Strategy BHU, School Health Center, Mixed BHU 
and Integrated BHU. The second part aimed to identify which partnerships were made for intra-sectoral and inter-sectoral actions for health.

The third part points to the results of the partnerships, such as improved monitoring of pregnant women, reduction of communicable diseases, control of drug abuse, environmental improvements and collaborated to the development of healthy habits. And the fourth part was elaborated based on the studies by Hope Corbin and collaborators(26) that showed in a wide scope review the constitutive elements of the best partnerships. They found nine constituent elements from which we selected five, as they answer the research questions: a)the development of shared mission to the objectives of the partnership; b)partnerships with various sectors; c)leadership that inspires trust and inclusion of new partners; d)building trust between partners and; e)the maintenance and evaluation of partnerships for continuous improvement.

The form was analyzed according to face validity and content validity. Face validity is determined by respondents who said whether the instrument appears to measure the characteristic of interest (27). We validate through the opinion of twenty-nine managers. They answered if the questions were clear and if the answers contemplated the characteristics of the BHU and the existence or absence of intra- and intersectoral actions.

Pilot test participants were the managers of social and environmental groupings ranked from one to four, $18.4 \%$ of managers out of scope answered the form. The analysis of the pilot test pointed to the need to reformulate some statements to submit the Likert scale(28) from the second to the fourth part of the form. We have added an answer option to some questions in the first part to address the diversity of contexts and understanding of the participants.

Content validity responds to what extent the instrument items effectively collect the information one wants to gather. We use smart PLS (Partial Least Square) 2.0 software and calculate Composite Reliability (CR) which is a more robust indicator of accuracy when compared to the alpha coefficient(29). To assess whether a sample is free of bias or if the set of answers are reliable we use CR. CR is a type of assessment of the relationships between indicators and constructs. Reliability values between 0.60 and 0.70 are considered adequate in exploratory research, while values of 0.70 and 0.90 are considered satisfactory for other types of research(30). We calculate the collinearity statistics: Internal and external Variance Inflation Factor (VIF) which detect multicollinearity. The VIF quantifies the extent of correlation between a predictor and the other predictors in a model. In this study in the proposed model, the CR was > 0.7 and the external VIF ranged from 1 to 3.2 .

\subsubsection{Quantitative Phase: Multiple Choice Form}

The variables were classified by the types of qualitative nominal and ordinal. The variable socioenvironmental groupings in health territories were of the dependent type. At the beginning of the form, we present the concept of "inter-sectoral actions" adopted in this research in order that the professionals understood how we were defining them. 
The validated online form was emailed to BHU managers from March to August 2018. The manager who was agreed to participate clicked in a web link entered a contact email, read the Informed Consent Form (ICF), and what if I agreed to participate then, would begin to answer the questions. The form had six questions about the BHU tips and its composition and statements followed by a five-point Likert scale (1 = strongly agree, 5 = strongly disagree) to assess the level of agreement with 11 statements: three about action practice intra-sectoral and 8 statements about inter-sectoral practices and the respective time of partnerships, constitutive elements of the partnerships and results achieved to identify the relationship between the nonexistence or existence of these practices with socio-environmental groupings in health territories.

\subsubsection{Qualitative phase: Focus groups}

At the end of the quantitative phase, we selected the BHU according to the selection criteria and invited professionals to participate in a focus group according to Van Den Hoonaard that considers it as open debate and an exchange of views(24). The groups were held in a BHU room, at a time previously agreed with the management, so as not to disturb the flow of care. We conducted a focus group in each of the 4 BHU selected and agreed to participate.

The focus group began with the presentation by the researcher, who said she was also a manager of an emergency service in the city center. She presented the research objectives and what would be the group dynamics. Participants read, signed CIF, allowed to turn on audio recording equipment, and the researcher took notes in the field diary during and after conversations with the group.

Then each member introduced himself, said his name and the characteristics of the micro areas and areas covered by BHU in which he operates. The researcher presented the concept of inter-sectoral actions and proposed to the participants to talk about "How inter-sectoral actions happen in the coverage area". As Van Den Hoonaard(2018) points out, this question worked as a guiding topic and whenever necessary the researcher asked for clarification to maintain the focus of the discussion(24).

\subsection{Research Context}

The research fieldwork was crossed by outbreaks of yellow fever, the resurgence of H1N1 influenza and low vaccination coverage in the municipality, which further increased the workload of professionals and contributed to lower availability to participate in this study. In this context, it was necessary to increase the time taken to collect and redo calls for managers to participate in the pilot test and the first quantitative phase, as well as to redo calls to request authorization for the focus group in the second phase.

This research focuses on all 279 coverage areas of the BHU of the five, six and seven most vulnerable groupings in the city, which require intra- and intersectoral actions to address health problems. The analysis of CElnfo showed the following characteristics of the most vulnerable groups: Grouping number five(131 areas): poor income, education and access conditions; Grouping number six(101 areas): poor 
family structure and access conditions and; Grouping number seven(47 areas): poor income and education and access conditions(8).

\subsubsection{Participants: quantitative phase}

Health service management is the segment of service management for which numerous ordinances and operating procedures are produced. It is the most complex link in the health system management structure and it can creatively mobilize resources to overcome everyday problems(31). According to this understanding, all BHU managers from the most vulnerable social and environmental groups were invited to respond to an online form indicating the existence of intra-sectoral and/or inter-sectoral actions as well as their respective outcomes and constitutions.

\subsubsection{Participants: qualitative phase}

The work of a multi-professional team advocated by Brazil's National Health System for comprehensive care is configured in the reciprocal relationship between the multiple technical interventions aimed at developing disease prevention and health promotion actions(32). In the second phase "which" we asked managers to nominate team members who work directly on inter-sectoral actions to participate in this survey. The twenty-six nominees were invited, but although they agreed to participate, two did not have time to attend the focus groups.

\subsection{Data Analysis}

\subsubsection{Data Analysis: Quantitative phase}

Quantitative form data was entered into a Microsoft Excel spreadsheet automatically after responses in the Google Docs tool. The identification of the BHU was requested for the selection of the second phase of research. Data were transferred to Jasp Statistic software (version 0.10) (33) for statistical analysis. We applied chi-square distribution technique to quantitatively assess the relationship between two nominal and ordinal variables. Bivariate analyses were performed by socio-environmental groupings relating to the existence of intra-sectoral and inter-sectoral actions and the partnerships of the territory. $P$ values $<0.05$ were considered significant.

\subsubsection{Data analysis: qualitative phase}

The literal audio transcripts were submitted for comment and approval by the survey participants and totaled 193 minutes of narrative. Based on Van Den Hoonaard's premise that he understands that the research participant is an expert of himself and that his answers may present new perspectives of knowledge, we follow the three steps of qualitative analysis proposed by her: a) open codification of transcriptions; b) identification of recurrent themes and their subthemes; and c) connection of themes and concepts interpreted in the light of social processes(24). The transcription was performed by a third person not linked to the research and this transcript was concerned not to change the information that was collected (full transcript). The data analysis was performed by the two researchers in this article. The 
transcribed excerpts that constituted the themes and subthemes were translated into English by the first author and checked by a bilingual professional in Portuguese and English.

\subsection{Mixing of quantitative and qualitative data}

We articulated the quantitative and qualitative data (Table 1) for the integration of these analyzes(25) which were represented in figure 2 .

\begin{tabular}{lll} 
Table 1 Summary of the methodological aspects of the research \\
\cline { 2 - 3 } & \multicolumn{2}{c}{ Mixed Method Search } \\
\cline { 2 - 3 } Participants & 170 managers from BHU & Qualitative \\
Data collect & Online form & 24 health professionals \\
Data Analysis & Descriptive and Inferential Statistics, Jasp Statistic, version 0.10 & 04 focus groups \\
\hline
\end{tabular}

\subsection{Ethical aspects}

After approval by the Ethics Committees in Research with Human Beings at the ABC School of Medicine (Presentation Certificate for Ethical Appreciation (PCEA): 56379615.5.0000.0082) and the SP Municipal Secretary of Health (MSH) (PCEA: 73401317.8.3001.0086) we ask SMS, Health Coordination and Supervision to disclose by email the approved research project and the research links.

\section{Results}

\subsection{Phase one: Quantitative}

A total of 191 managers answered the email inviting them to participate in the survey. Four managers did not want to participate and 17 answered the form twice which had their answers disregarded due to duplicity. After excluding the duplicates, 170 forms were analyzed, corresponding to $60.9 \%$ of the BHU managers of the social and environmental groupings of the highly vulnerable health territories (classified as five, six and seven respectively). Table 2 next presents the distribution of the number and percentage of participation by grouping.

\begin{tabular}{|c|c|c|}
\hline SGHT & Number of ternitories & Participants (\%) \\
\hline Five & 131 & 64.12 \\
\hline Six & 101 & 55.44 \\
\hline Seven & 47 & 63.82 \\
\hline
\end{tabular}


Participants who stated that they perform intra-sectoral actions correspond to $98.8 \%$ and those who perform inter-sectoral actions correspond to $99.4 \%$. The chi-square analysis revealed that there is no relationship between vulnerable SGHT and the existence of intra-sectoral and inter-sectoral actions (Table $3)$.

About intra-sectoral partners, the analysis demonstrates the relationship of the groupings with the following intra-sectoral partners: Other BHU $(p=0.009)$ and mental health services $(p=0.007)$ (Table 4$)$. There is also a significant relationship with some inter-sectoral partners: social assistance $(p=0.007)$, environment $(p=0.007)$ and Guardianship Council $(p=0.007)$ (Table 6).

Table 3 Relationship of the intra-sectoral and inter-sectoral actions and the SGHT of the most vulnerable

\begin{tabular}{|c|c|c|c|c|c|c|c|}
\hline & SGHT & Yes & $(\%)$ & No & $(\%)$ & Total & $\mathbf{p}$ \\
\hline \multirow[t]{4}{*}{ Existence of intra-sectoral actions } & Five & 83 & 98.8 & 1 & 1.2 & 84 & \multirow{4}{*}{0.765} \\
\hline & Six & 55 & 98.2 & 1 & 1.8 & 56 & \\
\hline & Seven & 30 & 100.0 & 0 & 0.0 & 30 & \\
\hline & Total & 168 & 98.8 & 2 & 1.18 & 170 & \\
\hline \multirow[t]{4}{*}{ Existence of inter-sectoral actions } & Five & 83 & 98.8 & 1 & 1.2 & 84 & \multirow{4}{*}{0.598} \\
\hline & Six & 56 & 100.0 & 0 & 0.0 & 56 & \\
\hline & Seven & 30 & 100.0 & 0 & 0.0 & 30 & \\
\hline & Total & 169 & 99.4 & 1 & 0.6 & 170 & \\
\hline
\end{tabular}

Managers fully agreed (69.3\%) that intra-sectoral health actions among the basic units take place in the groupings. The managers' statements regarding the existence of intra-sectoral actions for health between the BHU and the Psychosocial Care Centers (CAPS) happening in the groupings was higher: they agreed $(15.4 \%)$ or agreed $(75.0 \%)$ with statistical significance: $p<0.05$.

The managers of socio-environmental grouping six have the greater agreement of intra-sectoral actions with other BHU (23.21\% and $46.43 \%)$ and grouping five has the greater agreement of intra-sectoral actions with CAPS, (15.48\% and 75\%). The actions performed with another specialized sector had a greater disagreement in the different groupings. 
Table 4 Association of intra-sectoral actions with different partners in the most vulnerable SGHTs

\begin{tabular}{|c|c|c|c|c|c|c|c|c|}
\hline & SGHT & $\begin{array}{c}\text { Strongly agree } \\
(\%)\end{array}$ & $\begin{array}{c}\text { Agree } \\
(\%)\end{array}$ & $\begin{array}{l}\text { Neither agree nor } \\
\text { disagree (\%) }\end{array}$ & $\begin{array}{l}\text { Disagree } \\
(\%)\end{array}$ & $\begin{array}{c}\text { Strongly } \\
\text { disagree (\%) }\end{array}$ & $\begin{array}{c}\text { Total } \\
\text { (\%) }\end{array}$ & p \\
\hline \multirow[t]{4}{*}{$\mathrm{BHU}$ with other BHU } & Five & 9.5 & 61.9 & 7.14 & 17.9 & 3.6 & 100 & 0.009 \\
\hline & Six & 23.2 & 46.4 & 19.6 & 10.7 & 0 & 100 & \\
\hline & Seven & 0 & 63.3 & 20 & 16.7 & 0 & 100 & \\
\hline & Total & 12.4 & 57.1 & 13.5 & 15.3 & 1.8 & 100 & \\
\hline \multirow[t]{4}{*}{ BHU with CAPS } & Five & 15.5 & 75 & 3.6 & 3.6 & 2.4 & 100 & 0.007 \\
\hline & Six & 33.9 & 58.9 & 3.6 & 3.6 & 0 & 100 & \\
\hline & Seven & 13.3 & 60 & 20 & 6.7 & 0 & 100 & \\
\hline & Total & 21.2 & 67.1 & 6.8 & 4.1 & 1.2 & 100 & \\
\hline \multirow[t]{4}{*}{$\begin{array}{l}\text { BHU with the specialized } \\
\text { health sector }\end{array}$} & Five & 6 & 31 & 6 & 44.1 & 13.1 & 100 & 0.208 \\
\hline & Six & 5.4 & 32.1 & 16.1 & 39.3 & 7.1 & 100 & \\
\hline & Seven & 0 & 23.3 & 20 & 53.3 & 3.3 & 100 & \\
\hline & Total & 4.7 & 30 & 11.8 & 44.1 & 9.4 & 100 & \\
\hline
\end{tabular}

Table 5 shows the results of bivariate analyses using the chi-square test. There are statistically significant relationships between intersectoral actions and the following partners: social assistance $(p=$ $0.02)$, environment $(p=0.04)$ and the Guardianship Council $(p=0.004)$. The managers of the SGHT number 5 agreed in $85.7 \%$ regarding the existence of the partnership between $\mathrm{BHU}$ and social assistance, while the managers of the social and environmental groupings numbers 6 and 7 agreed on $83.9 \%$ and $73.3 \%$, respectively. The environment partners and Guardianship Council showed greater agreement (83.9\% and $69.6 \%$ ) with the BHU located in group 6. The managers of the BHU located in group 7 showed the lower agreement of the partnerships in relation to the other groups the Guardian Council which had $62.9 \%$. 
Table 5 Association of inter-sectoral actions of different partners and SGHT of the most vulnerable

\begin{tabular}{|c|c|c|c|c|c|c|c|c|}
\hline & SGHT & $\begin{array}{c}\text { Strongly agree } \\
(\%)\end{array}$ & $\begin{array}{c}\text { Agree } \\
(\%)\end{array}$ & $\begin{array}{c}\text { Neither agree nor disagree } \\
(\%)\end{array}$ & $\begin{array}{c}\text { Disagree } \\
(\%) \\
\end{array}$ & $\begin{array}{c}\text { Strongly disagree } \\
(\%)\end{array}$ & $\begin{array}{c}\text { Total } \\
(\%)\end{array}$ & $\mathbf{p}$ \\
\hline \multirow[t]{4}{*}{ BHU with education } & Five & 155 & 71.4 & 6.0 & 7.1 & 0 & 100 & \multirow[t]{4}{*}{0.212} \\
\hline & Six & 26.8 & 58.9 & 3.6 & 10.7 & 0 & 100 & \\
\hline & Seven & 13.3 & 83.3 & 3.3 & 0.0 & 0 & 100 & \\
\hline & Total & 18.8 & 69.4 & 4.7 & 7.1 & 0 & 100 & \\
\hline \multirow[t]{4}{*}{ BHU with social assistance } & Five & 11.9 & 73.8 & 4.8 & 9,5 & 0 & 100 & \multirow[t]{4}{*}{0.023} \\
\hline & Six & 19.6 & 64.3 & 7.1 & 5,4 & 3,6 & 100 & \\
\hline & Seven & 0.0 & 73.3 & 20.0 & 6.7 & 0.0 & 100 & \\
\hline & Total & 12.4 & 70.6 & 8.2 & 7.7 & 1.2 & 100 & \\
\hline \multirow[t]{4}{*}{ BHU with the environment } & Five & 13.1 & 59.5 & 14.3 & 13.1 & 0.0 & 100 & \multirow[t]{4}{*}{0.040} \\
\hline & Six & 19.6 & 64.3 & 7.1 & 3.6 & 5.4 & 100 & \\
\hline & Seven & 3.3 & 66.7 & 20.0 & 10.0 & 0.0 & 100 & \\
\hline & Total & 13.5 & 62.4 & 12.9 & 9.4 & 1.8 & 100 & \\
\hline \multirow[t]{4}{*}{ BHU with public safety } & Five & 2.4 & 23.8 & 25.0 & 44.1 & 4.8 & 100 & \multirow[t]{4}{*}{0.660} \\
\hline & Six & 1.8 & 19.6 & 28.6 & 37.5 & 12.5 & 100 & \\
\hline & Seven & 0.0 & 33.3 & 20.0 & 36.7 & 10.0 & 100 & \\
\hline & Total & 1.8 & 24.1 & 25.3 & 40.6 & 8.2 & 100 & \\
\hline \multirow[t]{4}{*}{ BHU with the religious sector } & Five & 4.8 & 39.3 & $21, .4$ & 29.8 & 4.8 & 100 & \multirow[t]{4}{*}{0.495} \\
\hline & Six & 7.1 & 48.2 & 19.6 & 17.9 & 7.1 & 100 & \\
\hline & Seven & 0.0 & 60.0 & 16.7 & 20.0 & 3.3 & 100 & \\
\hline & Total & 4.7 & 45.9 & 20.0 & 24.1 & 5.3 & 100 & \\
\hline \multirow[t]{4}{*}{ BHU with NGOs } & Five & 9.5 & 38.1 & 23.8 & 27.4 & 1.2 & 100 & \multirow[t]{4}{*}{0.080} \\
\hline & Six & 3.6 & 48.2 & 14.3 & 25.0 & 8.9 & 100 & \\
\hline & Seven & 3.3 & 63.3 & 16.7 & 13.3 & 3.3 & 100 & \\
\hline & Total & 6.5 & 45.9 & 19.4 & 24.1 & 4.1 & 100 & \\
\hline \multirow{4}{*}{$\begin{array}{l}\text { BHU with the Guardianship } \\
\text { Council }\end{array}$} & Five & 3.6 & 63.1 & 16.7 & 15.5 & 1.2 & 100 & \multirow[t]{4}{*}{0.004} \\
\hline & Six & 12.5 & 57.1 & 12.5 & 14.3 & 3.6 & 100 & \\
\hline & Seven & 0.0 & 40.0 & 40.0 & 10.0 & 10.0 & 100 & \\
\hline & Total & 5.9 & 57.1 & 19.4 & 14.1 & 3.5 & 100 & \\
\hline \multirow{4}{*}{$\begin{array}{l}\text { BHU with the Human Rights } \\
\text { Center }\end{array}$} & Five & 2.4 & 25.0 & 22.6 & 46.4 & 3.6 & 100 & \multirow[t]{4}{*}{0.668} \\
\hline & Six & 1.8 & 23.2 & 25.0 & 39.3 & 10.7 & 100 & \\
\hline & Seven & 0.0 & 13.3 & 26.7 & 53.3 & 6.7 & 100 & \\
\hline & Total & 1.8 & 22.4 & 24.1 & 45.3 & 6.5 & 100 & \\
\hline
\end{tabular}

\subsection{Phase two: Qualitative}


The researcher observed fragile housing, few cars on the streets, many people waiting for public transportation, poor sanitation, tangled wiring; and in the $\mathrm{BHU}$, as a general feature, walls with many posters that draw readers' attention to disease prevention or health promotion.

Ten BHU were invited to participate in the focus groups, four of which accepted. In each BHU, a single focus group was carried out, with an average duration of 50 minutes (maximum of 77 minutes and a minimum of 27 minutes). The four groups were conducted with 04 to 09 participants, of which only two are male, and included in all the following professional categories: eight CHA, five nurses, four nursing technicians, one psychologist, one physical therapist, one doctor, two managers, a pharmacist, and two administrative assistants.

The first one focal group with nine participants, the second one focus group with four participants, the third one focus group with five participants and the fourth focus group with seven participants. We identified an advantage in the difference in the information collected in relation to the number of people in each focus group: the larger focus groups presented a diversity of information while the smaller focus groups generated more detailed information. Participants reported the absence of professionals in group two due to extra activities at the BHU.

The diversity of professionals, the average 4.8 years worked at the BHU, the discussions among participants about the partnerships and the participation in inter-sectoral actions, indicates that the groups were representative and relevant to the research. There were no individual drop-outs or refusals to participate in focus groups or people present who did not participate in inter-sectoral actions. In the fourth group, we detected theoretical saturation because the data obtained started to present repetitions(27).

The themes that emerged from the qualitative data presented in table number 6 related to the characterization of the territory and relationship with the partners of intra-sectoral and inter-sectoral practices in health territories included:

\section{Theme 1: Social Inequalities and the Epidemiological Profile}

In this theme, two sub-themes were identified: chronic conditions by life cycle phases and social inequality between micro areas within the same territory.

\section{Chronic conditions by life cycle phases}

Participants described their territory at the beginning of the focus group. The context of the territories was characterized by different levels of vulnerability considering the life cycle stages or chronic health conditions. They also indicated that chronic diseases coexist with communicable diseases and violence at different stages of the life cycle.

"My micro area is full of problems (smirked laugh) ... My micro area is the main area core, there is a trap house (in Brazil the common name it is "biqueira", which is a common dialect to express a place where illegal drugs are sold), there are many teenagers, which I grew up with them and who are there today, 
working in drug trafficking. And also, alcoholism cases are very high in my micro area." (Focal group number 1).

"so there is tuberculosis, syphilis, hepatitis and there is a lot of HIV too. Are common diseases in this area ... And there is a lot of condyloma. And there are a lot of outbreaks too, diarrhea for example because here there is a vast extent of lack of ... sanitation" (Focal group number 1).

"... there are many children and pregnant women in my micro area and nothing more different than that, in the population itself in the area (not just in the micro area), there are many pregnant women, this population, in general, are needier (people very poor)..." (Focal group number 4).

\section{Social inequalities between micro areas}

Participants point to demographic and social inequalities between micro areas within the same coverage area. They show that the population suffers from different health problems that go beyond the walls of the health sector. While a micro area has no sanitation and children play in the contaminated stream exposed to epidemic phenomena, the elderly, hypertensive and diabetic are affected by violence in another micro area.

" the higher the status [social class], there are different kinds of illnesses ... those on the top have more serious illnesses than people in the lower social classes. Those who belong to the lower classes usually get diarrhea and vomit, or things like these. And those in the upper social classes are afflicted with diabetes, hypertension. They are more severe diseases not restricted to a specific class [social]" (Focal group number 4).

"... up here [in this micro area] there's a lot of violence: theft, things like that ... it's elderly, it's hypertensive, it's diabetic and most of them have medical insurance". (Focal group number 4).

\section{Theme 2: Building expanded health partnerships: individual and collective}

From this theme, two sub-themes were built: intra-sectoral and inter-sectoral arrangements established for people and intra-sectoral and inter-sectoral actions for collectivities.

\section{Intra-sectoral and inter-sectoral arrangements for people}

A set of complex problems experienced by a single person can lead to the formation of intra-sectoral and inter-sectoral partnerships in highly vulnerable territories. Intra-sectoral partnerships are built according to individual diagnostic and treatment needs while only inter-sectoral partnerships are those built because of socioeconomic vulnerability. While when professionals seek both intra-sectoral and inter-sectoral partnerships, they are mostly for people with chronicity and surrounded by complex socioeconomic situations, as long as the partnerships are not established and the socio-economic problem is managed. It is not possible to advance effective treatment and maintenance of well-being. To guide this work, the professional teams of some territories elaborate on the Singular Therapeutic Project (STP). 
The problem case of Magali, described in focus group number 3, clearly demonstrates this situation, as she is a transgender living with HIV and syphilis, worked as a sex worker and had no documents, which demanded the partnership with a specialized service in STDs/AIDS, as well as the social assistance that guided her in the making of documents, which were even necessary for her to receive antiretroviral treatment. In addition, the partnership with education made it possible for her to return to school and with the Specialized Referral Center for Social Assistance (CREAS), which offered a benefit so she could support herself while studying and looking for another profession because she wanted to stop prostituting herself.

Health professionals reported that they use other sectors, just as other sectors seek the BHU to solve installed problems. The most described intra-sectoral partnerships were with the CAPS and the intersectoral one was the school and social assistance equipment: Reference Center for Social Assistance (CRAS) and CREAS.

"Meetings, we perform STP[Singular Therapeutic Project] despite being a strategy, as the Belle's complex cases [CHA] right? that we can't handle. We also use intersectoriality. In STP, not only health that comes in, on the contrary, but we also have three STP proposals ... SUVIS [health surveillance supervision] depending on the case, the COVISA [Health Surveillance Coordination], the CAPS [Psychosocial Care Center], and the social care referral center CRAS [Reference Center for Social Assistance] also are triggered in specific cases" (Focal group number 3 ).

"So a transgender came here ... we identified her demand, drug user, she was also an escort, she had no fixed income and her income was from prostitution, she came to ask for help, she really came here saying that "I need help, I can't take this life anymore" and facing this situation, we went to work to help her. So she has Sexually Transmitted Infection (STI), both of them: HIV and syphilis, and then we went to work to help her ... she had no one official document so we did a super job to regulate that situation. She could not receive medicine in the public SAE [Specialized Care Service] due to a lack of official documents." (Focal group number 3).

\section{Intra-sectoral and inter-sectoral actions for collectivities}

The professionals to constitute partnerships for collectives go beyond the established actions, they too innovate in the search for new care practices in the territory, such as for example the Center for Natural Practices (CPN), Adolescent Living Center and Vale Sonhar Non-Governmental Organizations (NGOs), Afromix and Aclaerzinha offering actions to promote physical and mental health for different life cycles. They do not report intra-sectoral actions exclusive to the community but the combination of intra-sectoral and inter-sectoral actions. What sets action arrangements apart is durability: while arrangements are punctual constructions of partnerships, as in partnerships established to treat a person, as described above, actions endure in search of more lasting results in health promotion.

"...so what we could not solve here internally we asked for support from CRAS, went to CREAS, had a lot of abandonment, patient who really needed a legal endorsement and the offer of CPN which is a Center 
for Natural Practices which gave us a lot of support ... so out of this need: a huge patient waiting for line over two years old that we looked at had a schizophrenia IDC [International Disease Code], ie a patient with a complicated IDC, two years in the queue often just changing the prescription, what other forms of care we could offer to that patient at that time?". (Focal group number 3 ).

"And so does the Vale Dreaming project. At João Silva School also where the nursing assistant always goes to develop the actions, trained by the nurse and we also have the PSE and that is the health program at school, where I also take a period every month to be going there developing actions with him ... The PSE is something more organized where there is whole planning we sit and talk. Sometimes there is the theme that they want or we change that theme that we would have organized at that time and the CCA [Adolescent Living Center] is the same thing with me, APA, which is an Environmental Promotion Agent, an CHA and nursing assistant always be with me developing these actions"(Focal group number 4).

"...now we have a partnership with Afromix people who are also helping there on the walk they will even cover the court there, do you know?" (Focal group number 4).

Students and older people benefit most from partnerships that are often inter-sectoral. Intra-sectoral and inter-sectoral partnerships are aimed at groups of people in psychotic distress or family members of drug users with the largest partners being CAPS, CRAS and CREAS. In addition, the children and youth groups are covered by the Brazilian Program Health in School (PHS) and receive actions to promote oral health and prevention of immuno-preventable diseases.

"It is also the group that is a partnership with education, which is with oral health that leads to health in education that is the PSE. That enters both the medical part, as the nursing part and also the dental part. In the dental part, there is a new program we go to school to do the dental treatment of children called ART [Atraumatic Restoration]" (Focal group number 2).

"We have a lot of support from them [school] so, whenever they have a problem they come to us, we also delivery some demands to them" (Focal group number 1).

"The schools have already contacted us to do a search to see and such. It is with a kind of alteration at the level of abuse" (Focal group number 1).

"...all CAPS, three CAPS in total, have school participation sometimes, what else do you have? There are CREAS, there is the TJ [Court of Justice] depending on which case you are discussing and depending on the situation..." (Focal group number 2).

\section{Discussion}

This study of the two-phase sequential mixed method explored the relationship between intra-sectoral and inter-sectoral actions for health and the socio-environmental groupings of the most vulnerable health territories in the city of SP, presented the frequency of partnerships and the understanding of BHU professionals who experience these partnerships in their daily lives. 
We identified that professionals perform intra-sectoral and inter-sectoral arrangements and actions for health according to the characteristics of the people and communities of the territories although there is no statistical relationship between the most vulnerable groups and these actions (Figure 2). Indicating that there is no significant difference between the indexes of the groups and the existence of the actions, therefore the social and environmental vulnerability of the health territories may not be a single factor for the existence of the actions. Partnerships are being sought to deal with situations of violence, such as child maltreatment, as well as drug trafficking. However, the participants of this research report fear of violence, which is one of the limiting factors in the search for partnerships in the territories.

Whestpal and Mendes described that the health, education and social assistance sectors seem to be the most common partners when evaluating intrasectoral and intersectoral experiences in Brazil (34), a fact that is stimulated by the Brazilian macropolitics Bolsa Família Program (35). In this research the quantitative data studies pointed to the existence of intrasectoral partnerships of the BHU with other BHU and of the BHU with the CAPS and inter-sectoral partnerships between of the BHU with Social Assistance, the Environment Assistance and the Guardian Council with statistical significance $(p<0.05)$.

On the other hand, the results of the qualitative study showed two themes: a) Social inequalities and the epidemiological profile and b) Building partnerships for expanded health: individual and collective, which indicated that the triggers of intra-sectoral and inter-sectoral arrangements and actions for people or collectivities are chronic diseases involved with vulnerable socioeconomic aspects, actions to prevent immuno-preventable diseases and health promotion. Ferreira and collaborators also described intersectoral health actions in SP for one person: by uniting the expertise of doctors and veterinarians to investigate a case of psittacosis, they were able to prevent an epidemic (36).

The subthemes found, differentiate the arrangements of actions offered either to people or to collectivities. Arrangements expire when objectives are met, which are often linked to aspects of diseases aggravated by socioeconomic vulnerabilities. This coincides with recent documentary analysis by Fisher and colleagues who concluded that the inter-sectoral actions proposed by the health sector in Australia aimed to seek partnerships due to individual biomedical and/or behavioral approaches(37). The result of the literature review conducted by Garcia and collaborators that publications of Brazilian experiences in inter-sectoral actions for health lack information on sustainability(38), which may be due to lack of continuity as found in this study. Atkinson et al, in 2005 stated that Brazil was still more conservative in health care delivery with a greater focus on individual treatment once a problem was identified(39).

Unlike arrangements, intra-sectoral and inter-sectoral actions remain and professionals look for new ways to act and are usually present in actions aimed at health promotion. So there is no single way to intersect: for each problem case and unique context, there is an intra-sectoral or inter-sectoral arrangement or actions to expand health care in the territories. Although macro political approaches to inter-sectoral action are frequent in studies in countries such as Australia(40), Israel(41) and the United States(42), the present study found the development of inter-sectoral arrangements to respond to the demands of sick 
people, such as multidrug-resistant tuberculosis. and psychotic suffering, even with broader problems such as poor sanitation, drug trafficking and school dropout in the most vulnerable health territories of the city of SP.

Law 8080 of 1990 regulates health actions and services in the SUS. Advocates that inter-sectoral committees should be created to articulate national policies and programs of interest to health. It also advocates principles and guidelines that provide for comprehensive network assistance and at all levels of complexity(43). Thus, intra-sectoral and inter-sectoral actions are regulated in Brazilian legislation and were implemented in the researched areas, although in a biomedical and sectoral logic.

There was consistency between quantitative and qualitative data except for partnership with education, other BHU, environment, and the Guardian Council. The percentage of the education partnership was $88.23 \%$, being higher in the socio-environmental grouping number seven in the quantitative study, although it was not statistically significant. Unlike the qualitative study where professionals narrate the reciprocal search between schools and BHU. The opposite occurred in relation to partnerships with other $\mathrm{BHU}$ and the environment which were statistically significant in quantitative studies but were not cited in focus groups, which may indicate that these partnerships happen heterogeneously in some health territories and not in others.

There is a partnership with CAPS, which was also described by Mendel and collaborators who conducted evaluative research using a mixed-method and pointed to the effectiveness of networking to address depression care in underserved communities(44). This partnership happens, despite the difficulties, great demand for health services and lack of institutional guidelines for the realization of the partnership(45).

The environment sector in this study was considered by $83.9 \%$ of managers as one of the important partners of the BHU. This partnership can be justified by the adoption of the Environment, Green and Healthy Program (EGHP) by the city of SP, which since 2005 seeks to implement health promotion strategies considering the potential for the development of local and regional community projects that express an agenda of protection and promotion of green and healthy environments in the area where BHU operates(46).

In this study, the search for the Guardian Council as a partner was identified in more than sixty-nine percent of high-vulnerability groups, but professionals report fears of violence in seeking such a partnership, including combating child maltreatment. This fear probably permeates the medium-high score, which indicates the low search for partnerships with the sectors of Public Security and the Human Rights Center (CDHU), because professionals consider that there is no guarantee of anonymity of those who report, which makes them vulnerable to the perpetrators of such violence. This was also described by Egry and collaborators in an integrative documentary review and interview with health professionals from a highly vulnerable area of the city of SP where they point out the difficulties and weaknesses of the care network in addressing issues, the need for intersectoral actions and training of professionals to deal with situations of violence (47). 
To meet the complexity experienced by users of $\mathrm{BHU}$, professionals resorted to various partners, inside and outside the health. We found that while professionals are looking for partners to solve complex cases associated with illnesses and life situations, community leaders seek help with home visits to bedridden people, going to leisure spaces and sewing clothes for needy pregnant women. This was also described by Peters and colleagues who conducted a multi-method survey in the Netherlands, which points out that as broader objectives were agreed, more integration was visible and more partners and sectors were involved(48).

Rasanathan and colleagues can help to understand this by suggesting that low- and middle-income countries, including Brazil with unequally distributed middle income, where institutions are generally weak, and fragmentation, including the health sector, can ruin coordination of intersectoral policies(49).

In territories with high vulnerability, there are communicable and noncommunicable health problems, and people also suffer from violence and the ineffective presence of public authority, as also described by Unger and Riley (5). In this study, we conclude that specific intersectoral arrangements are constructed in the spaces of vulnerability that are focused on biomedical and sectorial logic. These arrangements are made, undone and redone as problem cases are known. In addition, intra-sectoral and inter-sectoral actions are carried out for communities that remain and transform to sustain disease prevention and health promotion actions.

\section{Limitations}

A limitation of this study that we recognize in the interpretation of the results. Some participants considered several practices that were not included in the definition of inter-sectoral partnerships indicating a high percentage of actions. The difference in conceptual interpretation has enriched the study because we can differentiate inter-sectoral actions, with sustainability for collectivities, from arrangements that are punctual and generally designed for people. Quantitative study participants may have generated clippings of territories that do not perform intra and / or intersectoral actions or that do not perform intra and / or intersectoral actions or that do but in view of the epidemic context, mentioned above, could not answer the form, but the participation was higher than $60 \%$.

Another limitation was that quantitative data were collected online. In addition, a selection bias may have affected our data due to the lack of participation in the Environmental Promotion Agent (EPA) focus groups, and its role is to work on inter-sectoral projects in the territory. Health Promotion and the results of the quantitative research points the environment sector one of the potential partners of the BHU.

\section{Conclusions}

The intra-sectoral and intersectoral practices developed in the health territories were carried out by health professionals from the BHU and professionals from other sectors of the coverage areas that make use of different technologies, formal and informal communications to transform individual or collective realities 
in search of welfare. These practices were driven by the needs of disease or the living conditions of people or communities. However, even aware of the need to seek partnerships, such as the Guardianship Council and the Human Rights Center to combat different types of violence, professionals' fear of retaliation for those who commit such violence leads them to avoid this important engagement.

This research identified the multiple contexts that drive health professionals to seek inter-sectoral engagements and which are the most frequent partners in poverty areas of the most populous metropolis of the Americas. Building personalized partnerships for expanded individual and collective health, to address social inequalities and; The chronic diseases and life cycle stages involved in socioeconomic weaknesses that generate more poverty are part of the professionals of the BHU. Thus intersectorialization was a practice developed for individuals and collectivities through various intrasectoral and/or intersectoral arrangements or actions.

Intra-sectoral and inter-sectoral actions need to become routine in the work of health professionals and other sectors in highly vulnerable health territory. The partnership of different fields of knowledge, such as health, education, law, and others, can strengthen professionals to act more effectively, achieving goals desired by all sectors.

\section{Abbreviations}

ART: Atraumatic Restoration

BHU: Basic Health Unit

CAPS: Psychosocial Care Centers

CCA: Adolescent Living Center

CDHU: Human Rights Center

CEInfo: Epidemiology and Information Coordination

CHA: Community Health Agents

COVISA: Health Surveillance Coordination

CNP: Center for Natural Practices

CR: Composite Reliability

CRAS: Reference Center for Social Assistance

CREAS: Specialized Referral Center for Social Assistance

EGHP: Environment, Green and Healthy Program 
EPA: Environmental Promotion Agent

FHS: Family Health Strategy

HIV: Human Immunodeficiency viruses

ICF: Informed Consent Form

IDC: International Disease Code

NGOs: Organizações não governamentais

QUAN: quantitative

qual: qualitative

PCEA: Presentation Certificate for Ethical Appreciation

PHC: Primary Health Care

PHS: Program Health in School

SAE: Specialized Care Service

SGHT: Socio-environmental Groupings in Health Territories

SP: São Paulo

STP: Singular Therapeutic Project

SUVIS: Supervisão de Vigilância em Saúde

TJ: Court of Justice

VIF: Variance Inflation Factor

\section{Declarations}

\section{Ethics approval and consent to participate}

The study was approved by the Research Ethics Committees of the ABC University Health Center (Presentation Certificate for Ethical Appreciation (PCEA): 56379615.5.0000.0082) and the São Paulo Municipal Secretary of Health (MSH) (PCEA: 73401317.8.3001.0086).

\section{Competing interests}


The authors declared no potential conflicts of interest with respect to the research, authorship, and/or publication of this article.

\section{Consent to publication}

We confirm that we have obtained consent to publish and report individual patient data.

\section{Availabilityy of data and materials}

The data sets used and analyzed during the current study are available from the corresponding author upon reasonable request.

\section{Funding}

The authors received no financial support for the research, authorship, and/or publication of this article.

\section{Acknowledgments}

The authors thank the members of the Statistical Analysis Department and the Study Design and Scientific Writing Laboratory, both from ABC University Center.

\section{Author information}

\section{Affiliations}

Department of Graduate Studies and Research. ABC Health University Center, Lauro Gomes Avenue, 2000 - Vila Sacadura Cabral, Santo André / São Paulo.

\section{Patricia Melo Bezerra}

Department of Graduate Studies and Research. ABC Health University Center, Lauro Gomes Avenue, 2000 - Vila Sacadura Cabral, Santo André / São Paulo.

lara Coelho Zito Guerriero

\section{Authors' Contributions}

The PMB researcher conducted the quantitative interviews and focus groups, as well as the analysis of quantitative data with the support of the Department of Statistical Analysis of the ABC University Health Center. The researchers PMB and ICZG analyzed the qualitative data, integrated the qualitative and quantitative data, wrote, read and approved the final manuscript.

\section{Corresponding author}

Correspondence to Patricia Melo Bezerra: patriciamelobe@gmail.com 


\section{References}

1. Lynch J, Smith GD, Hillemeier M, Shaw M, Raghunathan T, Kaplan G. Income inequality, the psychosocial environment, and health: Comparisons of wealthy nations. Lancet. 2001;358(9277):194200. doi: 10.1016/s0140-6736(01)05407-1. Accessed 20 February 2019. 2. Teixeira CF, Paim JS. Planejamento e programação de ações intersetoriais para a promoção da saúde e da qualidade de vida. Rev. Adm. Pública, v.34, n.6, p.63-80, 2000. Available from:

http://bibliotecadigital.fgv.br/ojs/index.php/rap/article/view/6348/4933. Accessed 20 February 2019. 3. Dubois A, St-Pierre L, Veras M. A scoping review of definitions and frameworks of intersectoral action. Cien Saude Colet [Internet]. 2015;20(10):2933-42. Available from: http://www.scielo.br/scielo.php? script=sci_arttext\&pid=S1413-81232015001002933\&Ing=en\&tlng=en. Accessed 20 February 2019. 4. Buss PM, Pellegrini Filho A. A saúde e seus determinantes sociais. Physis Rev Saúde Coletiva. 2007; 17 (1): 77-93. Available from: http://dx.doi.org/10.1590/S0103-73312007000100006. Accessed 20 February 2019. 5. Unger A, Riley LW. Slum health: From understanding to action. PLoS Med. 2007; 4(10): e295. Available from: https://doi.org/10.1371/journal.pmed.0040295. Accessed 20 February 2019. 6. NdumbeEyoh S, Moffatt $\mathrm{H}$. Intersectoral action for health equity: A rapid systematic review. BMC Public Health. 2013;13(1):1056. Available from: https://doi.org/10.1186/1471-2458-13-1056. Accessed 20 February 2019. 7. Jones J, Barry MM. Exploring the relationship between synergy and partnership functioning factors in health promotion partnerships. Health Promot Int. 2011; 26(4):408-20. doi:

10.1093/heapro/dar002. Accessed 20 February 2019. 8. São Paulo. Secretaria Municipal de Saúde. Coordenação de Epidemiologia e Informação (CEInfo). Agrupamentos Socioambientais dos Territórios da Saúde no Município de São Paulo. Boletim CElnfo, Análise IX Ano, n 10, São Paulo: Secretaria Municipal da Saúde, 2014. 9. City Mayors Statistics. Largest cities in the world. Available from:

http://www.citymayors.com/statistics/largest-cities-population-125.html. Accessed 20 February 2019. 10. Schumann LRMA, Moura LBA. Índices sintéticos de vulnerabilidade: uma revisão integrativa de literatura Vulnerability synthetic indices: a literature integrative review. Cienc e Saude Coletiva. 2015; 20(7) 2105-20. Available from: http://dx.doi.org/10.1590/1413-81232015207.10742014. Accessed 20 February 2019. 11. Brasil. Portaria No 2.436, De 21 De Setembro De 2017. Portaria No 2436. 2017. Available from: http://bvsms.saude.gov.br/bvs/saudelegis/gm/2017/prt2436_22_09_2017.html. Accessed 15 March 2019. 12. Decoster DP. Pourquoi faut-il « apprivoiser» la confiance entre tous pour cultiver un processus de développement local durable? Glob Health Promot. 2014; 21 (1) 31-35. Available from: https://doi.org/10.1177/1757975913512158. Accessed 10 March 2019. 13. World Health Organization. Primary Health Care: Now More Than Ever. The World Health Report 2008. Geneva: WHO. 2008. Available from: http://www.who.int/whr/2008/en/. 14. Kang E. Intersectoral collaboration for physical activity in Korean Healthy Cities. Health Promot Int. 2016;31(3):551-61. Accessed 15 March 2019. 15. Westphal MF. Municípios saudáveis: aspectos conceituais. Saúde e Soc. 2008; 6(2): 9-18. Available from: http://dx.doi.org/10.1590/S0104-12901997000200003. Accessed 15 March 2019. 16. Tooher R, Collins J, Braunack-Mayer A, Burgess T, Skinner SR, O’Keefe M, Watso M, Marshall HS. Intersectoral collaboration to implement schoolbased health programmes: Australian perspectives. Health Promot Int. 2017; 32(2): 312-21. https://academic.oup.com/heapro/article/32/2/312/3062464. 
Accessed 10 March 2019. 17. Heidemann ITSB, Wosny A de M, Boehs AE. Promoção da Saúde na Atenção Básica: estudo baseado no método de Paulo Freire. Cien Saude Colet. 2014; 19 (8) 3553-59. Available from: http://dx.doi.org/10.1590/1413-81232014198.11342013. Accessed 15 March 2019. 18. Becker D, Edmundo K, Bonatto D, Nunes NR, Souza R de. Empowerment e avaliação participativa em um programa de desenvolvimento local e promoção da saúde. Cien Saude Colet. 2004; 9 (3): 655-67. Available from: http://dx.doi.org/10.1590/S1413-81232004000300017. Accessed 15 March 2019. 19. Cynamon Cohen S, Eliasz Cynamon S, Cynamon Kligerman D, Facchetti Assumpção R. Habitação saudável no Programa Saúde da Família (PSF): uma estratégia para as políticas públicas de saúde e ambiente. Ciência e Saúde Coletiva. 2004; 9 (3): 807-13. Available from:

https://www.scielosp.org/scielo.php?pid=S1413-81232007000100022\&script=sci_abstract. Accessed 10 March 2019. 20. Carneiro ACLL, Souza V de, Godinho LK, Faria ICM de, Silva KL, Gazzinelli MF. Educação para a promoção da saúde no contexto da atenção primária. Rev Panam Salud Pública. 2012; 31(2):115-20. Available from: https://www.revistas.usp.br/reeusp/article/view/103198/101606. Accessed 10 March 2019. 21. Moretti AC, Teixeira FF, Suss FMB, Lawder JA de C, Lima LSM de, Bueno RE, Moysés SJ, Moysés ST. Intersetorialidade nas ações de promoção de saúde realizadas pelas equipes de saúde bucal de Curitiba (PR). Cien Saude Colet. 2010; 15 (1) 1827-34. Available from: http://dx.doi.org/10.1590/S1413-81232010000700095 Accessed 10 March 2019. 22. Sá LD de, Gomes ALC, Nogueira J de A, Villa TCS, Souza KMJ de, Palha PF. Intersetorialidade e vínculo no controle da tuberculose na Saúde da Família. Rev Enferm. 2011;19(2): 9. Available from: https://doi.org/10.1590/S0104-11692011000200022 .Accessed 10 March 2019. 23. Creswell JW, Plano Clark VL. Designing and conducting mixed methods research. 2nd. Los Angeles: SAGE Publications. 2011. 24. Hoonaard DK Van DK. Qualitative research in action: a Canadian primer. 3 ed. Ontario: Oxford. University Press Canada; 2018. 25. Dos Santos JLG, Erdmann AL, Meirelles BHS, Lanzoni GM de M, da Cunha VP, Ross R. Integração entre dados quantitativos e qualitativos em uma pesquisa de métodos mistos. Texto e Context Enferm. 2017; 26 (3): e1590016. Available from: http://dx.doi.org/10.1590/010407072017001590016. Accessed 10 March 2019. 26. Corbin JH, Jones J, Barry MM. What makes intersectoral partnerships for health promotion work? A review of the international literature. Health Promot Int [Internet]. 2016; daw061. Available from: https://academic.oup.com/heapro/articlelookup/doi/10.1093/heapro/daw061. Accessed 10 March 2019. 27. Vieira S. Medidas de confiabilidade. In: Como elaborar questionários. São Paulo: Atlas. 2009. p. 153-59. 28. Osinski IC, Bruno AS. Categorías de respuesta en escalas tipo likert. Psicothema. 1998; 10 (3): 623-31. Available from:

http://www.psicothema.com/psicothema.asp?id=191. 29. Sijtsma K. On the use, the misuse, and the very limited usefulness of cronbach's alpha. Psychometrika. 2009; 74 (1): 107-120.

http://www.psicothema.com/pdf/191.pdf Accessed 10 March 2019. 30. Hair, J. F., Hult, G. T. M., Ringle, C. M., \& Sarstedt M. Assessing PLS-SEM Results Part II: Evaluation of the Formative Measurement Models. In: Hair, J. F., Hult, G. T. M., Ringle, C. M., \& Sarstedt M. A Primer on Partial Least Squares Structural Equation Modeling (PLS-SEM). Thousand Oaks. Sage; 2013. p. 158-231. 31. Ferla AA. Prefácio. In: Franco CM, Santos SA, Salgado MF. Manual do Gerente: desafios da média gerência na saúde. Escola Nacional de Saúde Pública Sergio Arouca. 2011. 32. Moretti-Pires RO. Complexidade em saúde da família e formação do futuro profissional de saúde. Interface Commun Heal Educ. 2009; 13 (30): 153-66. Available 
from: http://dx.doi.org/10.1590/S1414-32832009000300013. Accessed 10 March 2019. 33. Love J, Selker R, Marsman M, Jamil T, Dropmann D, Verhagen AJ, Ly A, Gronau QF, Smira M, Epskamp S, Matzke D, Wild A, Knight P, Rouder JN, Morey RD, Wagenmakers, E.-J. JASP. (Version 0.10)[Computer software]. 2015. Available from: https://www.jstatsoft.org/article/view/v088i02. Accessed 05 March 2019. 34. Westphal MF, Mendes R. Cidade saúdavel: uma experiencia de interdisciplinaridade e intersetorialidade. Rev. Adm. Pública 2000; 34(6):47-61. http://bibliotecadigital.fgv.br/ojs/index.php/rap/article/view/6347 Accessed 18 November 2019. 35. Silva, LAL. Mecanismos da construção federal da intersetorialidade no Programa Bolsa Família: o papel das burocracias. Revista do Serviço Público, v. 64, n. 3, p. 327-350, 2013. https://doi.org/10.21874/rsp.v64i3.127. Accessed 18 November 2019. 36. Ferreira VL, Silva M V, Bassetti BR, Pellini ACG, Raso TF. Intersectoral action for health: preventing psittacosis spread after one reported case. Epidemiol Infect. 2017; 145(11): 2263-68. doi: 10.1017/S0950268817001042. Accessed 20 March 2019. 37. Fisher M, Baum FE, MacDougall C, Newman L, McDermott D, Phillips C. Intersectoral action on SDH and equity in Australian health policy. Health Promot Int. 2017;32(6):953-63. 32(6):95363. doi: 10.1093/heapro/daw035. Accessed 20 March 2019. 38. Garcia LMT, Maio IG, Santos TI dos, Folha CB de JC, Watanabe HAW. Intersetorialidade na saúde no Brasil no início do século XXI: um retrato das experiências. Saúde em Debate. 2014; 38 (103): 966-80. Available from:

http://dx.doi.org/10.5935/0103-1104.20140083. Accessed 20 March 2019. 39. Atkinson S, Cohn A, Ducci ME, Gideon J. Implementation of promotion and prevention activities in decentralized health systems: Comparative case studies from Chile and Brazil. Health Promotion International. 2005. 20(2):167-75. doi: 10.1093/heapro/dah605. Accessed 20 March 2019. 40. Andersen JB, Gulis G. Community maturity to implement Health in All Policies. Int J Public Health. 2017;62(5). 62(5):605-612. doi: 10.1007/s00038017-0951-z. Accessed 20 March 2019. 41. Kranzler Y, Davidovich N, Fleischman Y, Grotto I, Moran DS, Weinstein R. A health in all policies approach to promote active, healthy lifestyle in Israel. Isr J Health Policy Res. 2013; 2(1):16. doi: 10.1186/2045-4015-2-16. Accessed 20 March 2019. 42. Gase LN, Pennotti $\mathrm{R}$, Smith KD. "Health in all policies": Taking stock of emerging practices to incorporate health in decision making in the United States. J Public Heal Manag Pract. 2013;19(6):529-40. doi:

10.1097/PHH.0b013e3182980c6e. Accessed 20 March 2019. 43. Brasil. Poder Judiciário. Lei № 8.080, de 19 de setembro de 1990. Diário Of da União. 1990. Available from:

http://www.planalto.gov.br/ccivil_03/leis//8080.htm. Accessed 15 March 2019. 44. Mendel P, Ngo VK, Dixon E, Stockdale S, Jones F, Chung B, Jones A, Masongsong Z, Khodyakov D. Partnered evaluation of a community engagement intervention: Use of a kickoff conference in a randomized trial for depression care improvement in underserved communities. Ethn Dis. 2011;21(3 SUPPL. 1):1-21. Available from: https://www.ncbi.nlm.nih.gov/pmc/articles/PMC3582700/ Accessed 20 March 2019. 45. Delfini PS, Sato MT, Antoneli Pde P, Guimaraes PO. [Partnership between Psychosocial Care Center and Family Health Program: the challenge of a new knowledge construction]. Cien Saude Colet. 2009; 14( Suppl 1 ): 14831492. Available from: http://dx.doi.org/10.1590/S1413-81232009000800021. Accessed 20 March 2019. 46. De Sousa MF, Parreira CMSF. Ambiente Verdes e Saudáveis: contribuição dos Agentes Comunitários de Saúde na cidade de São Paulo, Brasil. 2010; 28 (5): 399-404. Accessed 20 March 2019. 47. Egry EY, Apostolico MR, Morais TCP. Reporting child violence, health care flows and work process of primary health care professionals. Cien Saude Colet. 2018; 23( 1 ): 83-92. Available from: 
http://dx.doi.org/10.1590/1413-81232018231.22062017. Accessed 20 March 2019. 48. Peters D, Harting J, Van Oers H, Schuit J, De Vries N, Stronks K. Manifestations of integrated public health policy in Dutch municipalities. Health Promot Int. 2016;31(2): 290-302. Available from:

https://doi.org/10.1093/heapro/dau104. Accessed 20 March 2019. 49. Rasanathan K, Bennett S, Atkins V, Beschel R, Carrasquilla G, Charles J, et al. Governing multisectoral action for health in low- and middleincome countries. PLoS Med. 2017; 14(4): e1002285. Available from:

https://doi.org/10.1371/journal.pmed.1002285. Accessed 20 March 2019. 